\title{
Gender Differences in Cognitive Abilites
}

\author{
${ }^{1}$ Ahmed A. Teleb and ${ }^{2}$ Aida A. Al Awamleh \\ ${ }^{1}$ Department of Psychology, The New Valley Faculty of Education, Assiut University, Egypt \\ ${ }^{2}$ Department of Instruction and Supervision, Faculty of Physical Education, University of Jordan, Jordan
}

Received 2012-09-15, Revised 2012-12-21; Accepted 2012-12-28

\begin{abstract}
The purpose of this study was to examine whether gender differences in Visual Selective Attention, Working Memory, Anticipation Time, Auditory Reaction Time and Visual-Motor Coordination performance existed. Forty eight students at Assiut university ( 21 males and 27 females; between 19.0 and 23.58 years old) participated in this study. Results indicated that there was no statistically significant difference between males and females in Visual Selective.
\end{abstract}

Keywords: Gender, Visual-Selective-Attention, Working-Memory, Reaction-Time, Visual-MotorCoordination

\section{INTRODUCTION}

Sex differences in human cognitive functioning are a controversial issue. A number of studies have investigated differences between females and males in Visual Selective Attention, Working Memory, Anticipation Time, Auditory Reaction Time and VisualMotor Coordination. Some researchers have repeatedly reported gender differences in cognitive abilities and brain organization, men's higher scores on spatial task. It has been reported that males tend to have larger brain volume, while the gray-to- white ratio tends to be grater in females (Allen et al., 2003; Gur et al., 2002; Shikhman, 2007). Others found males and females do not differ in spatial or identity negative priming (Koshino et al., 2000). Working memory can be defined simply as the memory that holds information that we are using the time (Wanlass, 2012). Gur et al. (2000) found gender differences in brain activation patterns in response to a judgment of line orientation task, with males showing right-lateralized increased in activation compared to female, whereas study cited by Speck et al. (2000) reveled greater activation in the left hemisphere in female, while males showed either bilateral activation. Study cited by Johnson and Bouchard (2007) showed that women displaying generally greater memory than male. On the other hand Voyer et al. (2007) indicted that
Females are somewhat more accurate in specific areas such as Memory for object locations in adolescent and adult samples, whereas other indicated that men tend to be more accurate in memory for visuospatial stimuli that are highly complex (Lewin et al., 2001). Study by Loring-Meier and Halpern (1999) found that males responded more quickly on all four tasks than women in making spatial judgments based on mental images. And their spatial working memory task that require recall of increasing longer sequences of spatial information were higher than female (Geiger and Litwiller, 2005; Kaufman, 2007). Some research shows that male advantage is evident in the spatial visualization and mantel rotation tests (Kaufman, 2007).

Merritt et al. (2007) indicated that there was limited empirical evidence indicating males and females might differ in selective attention and there was a clear need for more research in this area.

Gender differences in reaction time have been demonstrated in several studies (Dane and Erzurumlugoglu, 2003; Der and Deary, 2006; Riccio et al., 2001). Males have faster reaction times than females and female disadvantage is not reduced by practice (Noble et al., 1964; Welford, 1980; Adam et al., 1999; Dane and Erzurumlugoglu, 2003; Blough and Slavin, 1987). Women had slower simple reaction times than men (Der and Deary, 2006), whereas other research Corresponding Author: Ahmed A. Teleb, Department of Psychology, The New Valley Faculty of Education, Assiut University, Egypt 
suggests that while male were faster than female at aiming at a target, the female were more accurate (Barral and Debu, 2004).

Spierer et al. (2010) indicated that male athletes respond faster as compared with female athletes to both visual and auditory stimuli, which involved gross motor movement, whereas Silverman et al. (2007) indicated that such differences were relatively small. Lambourne (2006) indicated that no statistically significant differences were found in working memory capacity as a function of gender. Jausovec and Jausovec (2009) indicted that Gender differences were observed on the behavioral level only for the visual tasks; females display shorter reaction times than males.

\section{MATERIALS AND METHODS}

\subsection{Participants}

Data was collected from 48 healthy students (21 males; 27 females) from The New Valley Faculty of Education, Assiut University in Egypt, their ages were between 19 and 23.58 years with mean 19.88 and standard deviation 0.82 (males $19.71 \pm 0.59$ and females $20.02 \pm 0.96)$. There were no significant differences between groups on background variables including sex, mean age or mean years of education and all participants were right handed.

\subsection{Procedures}

All the tasks were administered individually in a psychology laboratory. After an initial session in which participants were informed about the objectives of the study.

\subsection{Measures}

The participants were required to take the following tasks (tests).

\subsection{Visual Selective Attention Task}

The basic method in this experiment was similar to the typical flanker task (derived from Eriksen and Eriksen, 1974). The target was horizontally flanked by two identical stimuli that were equally distant from it and the distance between the target and noise elements was either $1.7 \mathrm{~cm}$. In the present study, numerals were used as stimuli and the participants had to judge the parity, either 'even' or 'odd' of the target stimulus in a flanker task (Fig. 1 for an example). They had to press a left mouse button for even and a right mouse button for odd numbers. The stimuli presented on a white frame painted on a black background. The display of target and flankers presented within a frame.

In half of the trials the flankers were congruent (i.e., the flankers were associated with the same response as the target) and on the other half, they were incongruent (i.e., the flankers were associated with a different response from the target). Target and flankers were always different. Each participant completed three blocks of 64 trials that began with the mapping instructions.

As showen from Fig. 2, each trial started with the appearance of a fixation cross which was drawn at the center of the dark screen for $300 \mathrm{~ms}$. After a blank screen of 400-ms duration, the stimuli were presented replacing the fixation point (displayed for $200 \mathrm{~ms}$ ). The program waited until the response was given and then the fixation cross for the next trial appeared. Response with the wrong key were counted as errors, in this case, auditory error feedback was given.
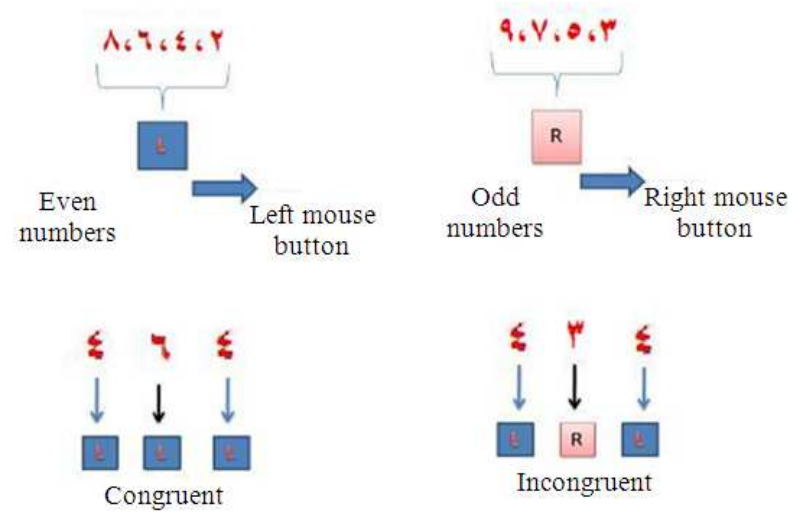

Fig. 1. Eriksen flanker task

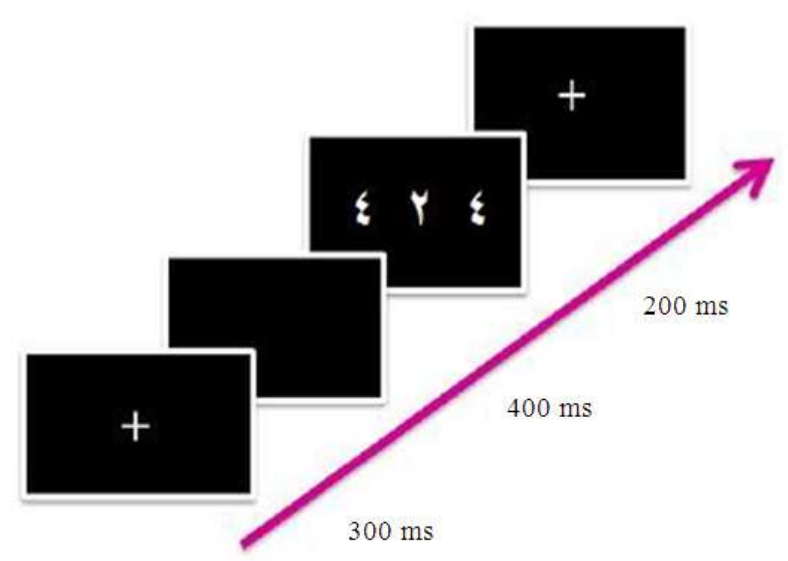

Fig. 2. The sequence of a single trial in the Flanker paradigm task. Stop-signal task 
The general instructions included a general description of the task "in each trial, you will be presented with three stimuli. You need to respond only to the stimulus in the centre and ignore all other stimuli", followed by an example of possible categorization that was not used in the experimental blocks (i.e., odd and even digits mapped to the right and left mouse button, respectively). The last part of the instructions indicated, "In the next step you will start. Prepare yourself. Press the space bar when ready". During the instructions, the participants were asked to avoid simulating any button press. Participants were seated about $50 \mathrm{~cm}$ from the computer monitor. In the beginning of the experiment, the participants executed one block to familiarize themselves with the task structure. This block was based on 45 a set of instructions and stimuli that were not used in the subsequent blocks. It considered as practice, included 64 trials and not analyzed.

The present study used stop-signal task that derived from Logan and Cowan (1984) to measure the performance monitoring and response inhibition. A laboratory task provided a direct measure of the speed with which one can execute and voluntarily inhibit a motor response.

In the stop-signal task, all participants did one practice and three experimental blocks with 64 trials in each on this task. Twenty five percent $(25 \%)$ of the trials were stop trials. The duration of the stop signals, which are $1 \mathrm{kHz}$ tones produced by a function generator, was $100 \mathrm{~ms}$, each trial began with a $500 \mathrm{~ms}$ presentation of a fixation point $(+$ sign presented at the centre of the screen). The presentation of the stimulus (displayed for $165 \mathrm{~ms}$ ) then followed. The stimulus appeared on the middle of the screen within each block and the stop signals were presented after the presentations of the stimulus. A go trial always followed a stop trial, except once in each block, where there were two stop signals. The duration between the fixation point and appearance of the stimulus was $200 \mathrm{~ms}$, the participant selected odd and even digits mapped to the right and left mouse, respectively. In the stop-signal task, the program did not wait until the participant responded, but continued if he or she did not respond within $1500 \mathrm{~ms}$ after stimulus onset. In the beginning of the experiment, the 48 participants executed one block as practice and this block not analyzed. Participants instructed to respond as quickly and as accurately as possible. (Dr. Ing. Husain Aljazzar helped the first author in this study to programe this task).

\subsection{Working Memory Task}

Working Memory Task was designed according to modified Sternberg task. Each trial began with the presentation of two lists of words, one above the other, centered on the computer screen. The top list presented in red and the bottom list in blue on a black background. The length of the two lists varied independently; each list consisted of either one or three words. The lists were presented simultaneously for $1.3 \mathrm{sec}$ multiplied by the total number of words (i.e., $2600 \mathrm{~ms}$ between the lists of one word; $5200 \mathrm{~ms}$ between the list of one word and three words and $7800 \mathrm{~ms}$ between the lists of three words). $700 \mathrm{~ms}$ after the memory lists disappeared, a frame was displayed in the center of the screen. In half of the trials, the frame was red and in the other half, it was blue, determined at random. The probe word was displayed within the frame in the same color after 200 ms. Participants were asked to decide whether the probe was in the relevant list as quickly and accurately as possible by pressing the left mouse button for "Yes" and the right mouse button for "No." The feedback tone told the participants whether they were right or wrong. In half of the trials, the cue was a frame of the same color as that for the first probe, thus requiring no switch of the relevant list, whereas in the other half, the cue required a switch to the other, previously irrelevant list. Figure 3 gives an example of Working memory task.

There were three kinds of probes for both comparisons. Half of them were positive probes, that is, words from the relevant list that were to be accepted. The other half consisted of $25 \%$ intrusion probes, that is, words from the currently irrelevant list and $25 \%$ new probes 47 not contained in both lists. New probes were not used in any previous memory list in the whole block.

This task consisted of three blocks with 64 trials each. The 64 trials of each block were generated by crossing length of the red list (1 vs. 3), length of the blue list (1 vs. 3 ), switch of relevant list from first to second probe (switch vs. no switch) and probe type of the first probe (positive, new and intrusion). With the constraint that there were 32 positive probes and 16 each of new and intrusion probes in each block. (Dr. Ing. Husain Aljazzar helped the first author in this study to programe this task).

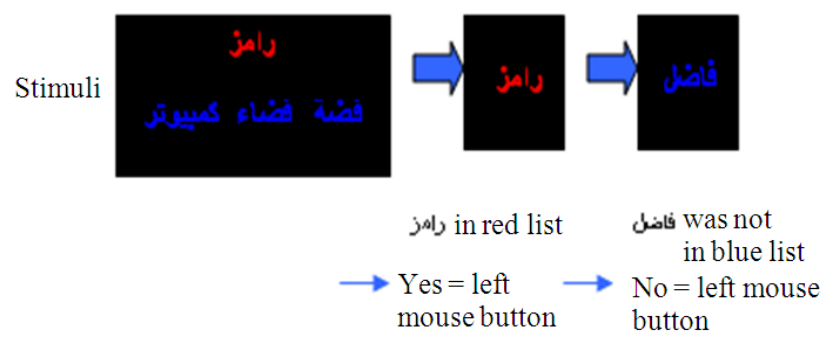

Fig. 3. Working memory task 


\subsection{Visual-Motor Co-Ordination Task}

Visual-motor coordination was measured by using Photoelectric Rotary Pursuit Apparatus (Lafayette Instrument, model 30013). Each participant underwent three testing trails of motor learning using the rotary pursuit task. The first trail was at the beginning of the experiment. The second trail was $60 \mathrm{~min}$ after the first trail. The third trail was $30 \mathrm{~min}$ after the second trail. The rotary pursuit apparatus presented a three-quarters inch circle target that rotated clockwise in a circular path (the circle is 12 inch diameter). During each trial, participants were required to hold a stylus on a flat surface under which the target rotated and to follow the target as it moved about its path, the speed of the target was 10 rotation-per-minute (RPM=10 rotationper-minute). A photoelectric device measured the numbers of errors (error; each time the stylus did not follow the target correctly or Time-Off-Target) that the stylus was held correctly over the target for each trial. Each trial was $20 \mathrm{sec}$ long. The mean of errors across all three trials was calculated.

\subsection{Auditory Reaction Time Task}

Auditory Reaction Time was measured by using Deluxe Multi-Choice Reaction Time Apparatus (Lafayette Instrument Company, model 63013). Respectively, each participant underwent three testing trails of auditory reaction time task using the multichoice reaction time task. An apparatus consists of three units; (1) multi choice reaction time, (2) voice response time control and third: response keyboard with stimulus unit. During each trial, participants heard only an electronic voice $(2800 \mathrm{~Hz}$, from the first unit, after $3 \mathrm{sec}$ after the researcher push INITIAT button) and then they were required to push the middle button box (as determinates from response sector) in the third unit, at the same time, the digital clock registers auditory reaction time in 1/100th second. The mean of reaction time across all three trials was calculated.

\subsection{Anticipation Time Task}

Anticipation time is a measure of one's perception of motion and visual estimation of speed. It involves a subject responding to a moving stimulus so that the subject's response coincides with the arrival of the stimulus. Anticipation time was measured by using
Bassin Anticipation Timer (Lafayette Instrument Company, model 50575). An apparatus consists of three units; first: bassing timer (or control screen), second: one $1.52 \mathrm{~m}$ gutter with 32 diodes placed on it linearly and third: response button. The screen has a digital display, with commands that permit the operator to control the stimulus propagation speed and the preparatory interval speed. Once activated, the screen exhibits an alert signal and, after the preparatory interval, it initiates the propagation of a luminous stimulus, lighting the 32 diodes successively. The task required participants to press the response button simultaneously with the illumination of the last diode. The digital display showed the error measure (em): that is, the difference between the illumination of the last diode and the response. Each participant underwent three testing trails of anticipation reaction time task. During each trial, participant waits $2 \mathrm{sec}$ (as waiting time) while he holds the button and the light running with $3 \mathrm{mph}$ (as runway speed). Participant was required to observe the lights and make response (push the button) coincident when the light arrive to the final point, at the same time, the digital clock registers anticipation time (early or late) in $1 / 100$ th second. The mean of anticipation time across all three trials was calculated.

\section{RESULTS}

All statistical analyses were run in SPSS18. The level of significance was set at .05 in all statistical analyses. Table 1 presents the mean scores obtained by men and women on each of the cognitive abilities tasks, (Visual Selective Attention, Working Memory, Anticipation Time, Auditory Reaction Time and VisualMotor Coordination).

The result of t-test for the two groups of male and female students indicated no significant difference in terms of mean scores obtained in Visual Attention test with error p-value (-1.573) and RT(M) p-value $(-0.763)$. Significant differences weren't found in Working Memory intrusion (word) test with error pvalue (1.528) and RT(M) p-value (0.088) and Serial Length, switch (colour) with error p-value (1.344) and $(0.830)$ and p-value (0.908) and (-0.346) respectively. There were no statistically significant differences in Anticipation Time, Auditory Reaction Time and Visual-Motor Coordination tests. 
Ahmed A. Teleb and Aida A. Al Awamleh / Current Research in Psychology 3 (1) (2012) 33-39

Table 1. Differences between men and women in visual selective attention, working memory, anticipation time, auditory reaction time and visual-motor coordination

\begin{tabular}{|c|c|c|c|c|c|}
\hline \multirow[b]{2}{*}{ Variables } & \multicolumn{2}{|c|}{ Males (21) } & \multicolumn{2}{|c|}{ Females (27) } & \multirow[b]{2}{*}{$\mathrm{t}$-test } \\
\hline & $\mathrm{m}$ & Std & $\mathrm{m}$ & Std & \\
\hline \multicolumn{6}{|l|}{ Visual attention } \\
\hline Errors (\%) & 11.52 & 13.41 & 18.02 & 14.80 & -1.573 \\
\hline RT (M) & 1020.63 & 967.67 & 2545.15 & 9097.48 & -0.763 \\
\hline \multicolumn{6}{|l|}{ Working Memory-Intrusion (word) } \\
\hline Errors $(\%)$ & 29.74 & 30.32 & 18.85 & 18.81 & 1.528 \\
\hline $\mathrm{RT}(\mathrm{M})$ & 1513.62 & 420.92 & 1499.75 & 609.65 & 0.088 \\
\hline \multicolumn{6}{|l|}{-Serial length } \\
\hline Errors $(\%)$ & 27.31 & 28.67 & 18.57 & 15.79 & 1.344 \\
\hline $\mathrm{RT}(\mathrm{M})$ & 1007.95 & 468.55 & 905.05 & 315.39 & 0.908 \\
\hline \multicolumn{6}{|l|}{-Switch (colour) } \\
\hline Errors $(\%)$ & 28.40 & 27.06 & 22.97 & 18.18 & 0.830 \\
\hline $\mathrm{RT}(\mathrm{M})$ & 1550.46 & 583.47 & 1617.15 & 715.95 & -0.346 \\
\hline Anticipation Time Task & 359.50 & 273.30 & 355.30 & 263.30 & 0.053 \\
\hline Auditory Reaction Time & 480.60 & 60.64 & 545.00 & 123.90 & -2.151 \\
\hline Visual-Motor Coordination (N. of Errors) & 3.95 & 0.74 & 3.96 & 0.71 & -0.050 \\
\hline
\end{tabular}

\section{DISCUSSION}

The aim of this study was to explore sex differences in Visual Selective Attention, Working Memory, Anticipation Time, Auditory Reaction Time and Visual-Motor Coordination. Findings of gender differences did not show any difference in visual selective attention which is considered a central component of cognitive functioning.

Feng et al. (2011) study found gender differences in visual reflexive attention shifting. They indicated that Gender differences in visual attention shifting may moderate or contribute to gender differences in other cognitive activities.

Although study cited by Merritt et al. (2007) found that males and females showed differential responses in an endogenously cued visual selective attention task, females showed increased costs to an invalid cue and while males benefit from an invalid cue compared to nocue control condition, while other studies did not (Koshino et al., 2000). Data did not demonstrate differences in reaction time between men and women while gender differences have been reported in a number of studies (Dane and Erzurumlugoglu, 2003; Der and Deary, 2006; Riccio et al., 2001; Noble et al., 1964; Welford, 1980; Adam et al., 1999; Barral and Debu, 2004; Spierer et al., 2010).

Females had shorter reaction time than males of verbal than figural task (Jausovec and Jausovec, 2009).

No sex differences were found in working memory. These findings are consistent with previous research
(Lambourne, 2006; Rahman et al., 2011) and are inconsistent with Kaufman (2007). Research showed male advantage in the spatial visualization and mantel rotation tests further more researches cited by Harness et al. (2008) and Voyer et al. (2007) demonstrated that female advantage on the visual working-memory task and showed significantly greater recall than men. In this study male and female subjects did not differ in either in intrusion errors or serial length or switch (colour) in and working memory. These findings are consistent with Boyle et al. (2010) that found no significant sex difference observed on the visual-spatial matching task.

Coluccia and Louse (2004) indicted that gender differences are due to different strategies used to solve orientation tasks and there are an influence of biological and socio/cultural factors.

It is clear that for an unambiguous interpretation of performance on cognitive tasks, various researchers attribute such kind of differences to either genetic or sex factors present in the newborn, while others suggest that major differences emerge at a later stage and are mainly due to personality, educational and social factors and that consequently the term "gender" is more appropriate (Cornoldi and Vecchi, 2003).

\section{CONCLUSION}

In this study, the focus was on visual selective attention, working memory, anticipation time, auditory reaction time and visual-motor coordination cognitive ability. Data demonstrated no gender differences in such 
variables. Further studies are recommended to determine the generalizability of the study findings and even though gender differences were not existed, it is recommended that effects of sex differences must be taken into account when designing experiments into human cognition.

\section{ACKNOWLEDGEMENT}

The first researcher in this study (during his postdoctoral scholarship in Constance University) is greatly indebted to Dr.-Ing. Husain Aljazzar (specialist for software engineering and software project management, currently associated with Bosch Security Systems, Munich, Germany) for his cooperation, strenuous effort, guidance and skilled assistance that helped him to get the two tasks: selective visual attention task and working memory task.

\section{REFERENCES}

Adam, J., F. Paas, M. Buekers, I. Wuyts and W. Spijkers et al., 1999. Gender differences in choice reaction time: Evidence for differential strategies. Ergonomics, 42: 327-335. DOI: $10.1080 / 001401399185685$

Allen, J.S., H. Damasio, T.J. Grabowski, J. Bruss and W. Zhang, 2003. Sexual dimorphism and asymmetries in the gray-white composition of the human cerebrum. Neuroimage, 18: 880-894. DOI: 10.1016/S1053-8119(03)00034-X

Barral, J. and B. Debu, 2004. Aiming in adults: Sex and laterality effects. Laterality, 9: 299-312. DOI: $10.1080 / 13576500342000158$

Blough, P.M. and L.K. Slavin, 1987. Reaction time assessments of gender differences in visual-spatial performance. Percep. Psychophys., 41: 276-281. DOI: $10.3758 / \mathrm{BF} 03208225$

Boyle, G.J., D.L. Neumann, J.J. Furedy and H.R. Westbury, 2010. Sex differences in verbal and a visual-spatial tasks under different hemispheric visual-field presentation conditions. Perceptual Motor Skills, 110: 396-410. DOI: 10.2466/pms. 110.2.396-410

Coluccia, E. and G. Louse, 2004. Gender differences in spatial orientation: A review. J. Environ. Psychol., 24: 329-340. DOI: 10.1016/j.jenvp.2004.08.006

Cornoldi, C. and T. Vecchi, 2003. Visuo-Spatial Working Memory and Individual Differences. 1st Edn., Taylor and Francis Group, Hove, ISBN-10: 1841692166, pp: 169.
Dane, S. and A. Erzurumluoglu, 2003. Sex and handedness differences in eye-hand visual reaction times in handball players. Int. J. Neurosci., 113: 923-929. DOI: 10.1080/00207450390220367

Der, G. and I.J. Deary, 2006. Age and sex differences in reaction time in adulthood: Results from the United Kingdom health and lifestyle survey. Psychol. Aging, 21: 62-73. DOI: 10.1037/0882-7974.21.1.62

Eriksen, B.A. and C.W. Eriksen, 1974. Effects of noise letters upon the identification of a target letter in a nonsearch task. Percep. Psychophys., 16: 143-149. DOI: $10.3758 /$ BF03203267

Feng, Q., Y. Zheng, X. Zhang, Y. Song and Y.J. Luo et al., 2011. Gender differences in visual reflexive attention shifting: Evidence from an ERP study. Brain Res., 1401: 59-65. DOI: 10.1016/j.brainres.2011.05.041

Geiger, J.F. and R.M. Litwiller, 2005. Spatial working memory and gender differences in science. J. Instruct. Psychol., 32: 49-57.

Gur, R.C., D. Alsop, D. Glahn, R. Petty and C.L. Swanson et al., 2000. An fMRI study of sex differences in regional activation to a verbal and a spatial task. Brain Language, 74: 157-170. DOI: 10.1006/brln.2000.2325

Gur, R.C., F. Gunning-Dixon, W.B. Bilker and R.E. Gur, 2002. Sex differences in temporo-limbic and frontal brain volumes of healthy adults. Cereb Cortex, 12: 998-1003. DOI: $10.1093 /$ cercor/12.9.998

Harness, A., L. Jacot, S. Scherf, A. White and J.E. Warnick, 2008. Sex differences in working memory Psychol. Rep., 103: 214-218. DOI: 10.2466/PR0.103.5.214-218

Jausovec, N. and K. Jausovec, 2009. Gender related differences in visual and auditory processing of verbal and figural tasks. Brain Res., 1300: 135-145. DOI: 10.1016/j.brainres.2009.08.093

Johnson, W. and T.J. Bouchard, 2007. Sex differences in mental abilities: $G$ masks the dimensions on which they lie. Intelligence, 35: 23-39. DOI: 10.1016/j.intell.2006.03.012

Kaufman, S.B., 2007. Sex differences in mental rotation and spatial visualization ability: Can they be accounted for by differences in working memory capacity? Intelligence, 35: 211-223. DOI: 10.1016/j.intell.2006.07.009

Koshino, H., G.A. Boese and F.R. Ferraro, 2000. The relationship between cognitive ability and positive and negative priming in identity and spatial priming tasks. J. General Psychol., 127: 372-382. DOI: $10.1080 / 00221300009598591$ 
Lambourne, K., 2006. The relationship between working memory capacity and physical activity rates in young adults. J. Sports Sci. Med., 5: 149-153.

Lewin, C., G. Wolgers and A. Herlitz, 2001. Sex differences favoring women in verbal but not in visuospatial episodic memory. Neuropsychology, 15: 165-173. DOI: 10.1037/0894-4105.15.2.165

Logan, G.D. and W.B. Cowan, 1984. On the ability to inhibit thought and action: A theory of an act of control. Psychological Rev., 91: 295-327. DOI: 10.1037//0033-295X.91.3.295

Loring-Meier, S. and D.F. Halpern, 1999. Sex differences in visuospatial working memory: Components of cognitive processing. Psychonomic Bull. Rev., 6: 464-471. DOI: 10.3758/BF03210836

Merritt, P., E. Hirshman, W. Wharton, B. Stangl and J. Devlin et al., 2007. Evidence for gender differences in visual selective attention. Personality Indiv. Differ., 43: 597-609. DOI: 10.1016/j.paid.2007.01.016

Noble, C.E., B.L. Baker and T.A. Jones, 1964. Age and sex parameters in psychomotor learning. Perceptual Motor Skills, 19: 935-945. DOI: 10.2466/pms.1964.19.3.935

Rahman, Q., M. Bakare and C. Serinsu, 2011. No sex differences in spatial location memory for abstract designs. Brain Cognition, 76: 15-19. DOI: 10.1016/j.bandc.2011.03.012

Riccio, C.A., C.R. Reynolds and P.A. Lowe, 2001. Clinical Applications of Continuous Performance Tests: Measuring Attention and Impulsive Responding in Children and Adults. 1st Edn., John Wiley and Sons, New York, ISBN-10: 0471380326, pp: 408.
Shikhman, M., 2007. Age, Gender, General Intelligence and Educational Level Influences on Working Memory. 1st Edn., City University of New York, USA., ISBN-10: 0549267816, pp: 107.

Silverman, I., J. Choi and M. Peters, 2007. The huntergatherer theory of sex differences in spatial abilities: Data from 40 countries. Arch. Sexual Behav., 36: 261-268. DOI: 10.1007/s10508-006-9168-6

Speck, O., T. Ernst, J. Braun, C. Koch and E. Miller et al., 2000. Gender differences in the functional organization of the brain for working memory. Neuroreport, 11: 2581-2585. DOI: 10.1097/00001756-200008030-00046

Spierer, D.K., R.A. Petersen, K. Duffy, B.M. Corcoran and T. Rawls-Martin, 2010. Gender influence on response time to sensory stimuli. J. Strength Condition. Res., 24: 957-964. DOI: 10.1519/JSC.0b013e3181c7c536

Voyer, D., A. Postma, B. Brake and J. ImperatoMcGinley, 2007. Gender differences in object location memory: A meta-analysis. Psychonomic Bull. Rev., 14: 23-38. DOI: 10.3758/BF03194024

Wanlass, R.L., 2012. The Neuropsychology Toolkit: Guidelines, Formats and Language. 1st Edn., Springer, New York, ISBN-10: 1461418828, pp: 160.

Welford, A.T., 1980. Choice Reaction Time: Basic Concepts. In: Reaction Times, Welford, A.T. (Ed.), Academic Press, New York, ISBN-10: 0127428801, pp: 73-128. 